\title{
Hep88 mAb-Mediated Paraptosis-Like Apoptosis in HepG2 Cells via Downstream Upregulation and Activation of Caspase-3, Caspase-8 and Caspase-9
}

\author{
Thantip Mitupatum ${ }^{1}$, Kalaya Aree ${ }^{1}$, Suthathip Kittisenachai $^{2}$, Sittiruk Roytrakul $^{2}$, \\ Songchan Puthong ${ }^{3}$, Sasichai Kangsadalampai ${ }^{1}$, Panadda Rojpibulstit ${ }^{1 *}$
}

\begin{abstract}
Hepatocellular carcinoma (HCC) is a leading cause of cancer death worldwide. Presently, targeted therapy via monoclonal antibodies to specific tumor-associated antigens is being continuously developed. Hep88 $\mathrm{mAb}$ has proven to exert tumoricidal effects on the HepG2 cell via a paraptosis-like morphology. To verify the pathway, we then demonstrated downstream up-regulation of caspase-3, caspase-8 and caspase-9, assessingmRNA expression by real-time PCR and associated enzyme activity by colorimetric assay. Active caspase-3 determination was also accomplished by flow cytometry. Active caspase-3 expression was increased by Hep88 mAb treatment in a dose-and time-dependent manner. All of the results indicated that $\mathrm{Hep88} \mathrm{mAb}$ induced programmed cell death in the HepG2 cell line from paraptosis-like to apoptosis by downstream induction of caspases. These conclusions imply that Hep88mAb might be a promising tool for the effective treatment of HCC in the future.
\end{abstract}

Keywords: Hepatocellular carcinoma - Hep88 monoclonal antibody - paraptosis - caspase

Asian Pac J Cancer Prev, 16 (5), 1771-1779

\section{Introduction}

Currently, the leading causes of death in the world have changed from accidental or infectious diseases to cancer. Cancer-caused worldwide death accounted for 7.6 million deaths (around 13\% of all deaths) in 2008 (Ferlay et al., 2010). In Thailand, cancer is also becoming a significant health problem. The same holds true for all other countries, as it is their leading cause of death (Somboon et al., 2014). Among these, the leading type of cancer in males and the third in females is Hepatocellular carcinoma (HCC) (National cancer Institute of Thailand, 2011), while this type of cancer is the fifth most common cancer worldwide.

The main etiology for HCC in Thailand is hepatitis B virus (HBV) infection, while, worldwide, the dominant etiologies are chronic infection of hepatitis $\mathrm{B}$ virus (HBV), hepatitis $\mathrm{C}$ virus (HCV), alcohol and aflatoxin ingestion. These agents alter the function of groups of genes involved in the control of cell growth, apoptosis and DNA repair. As a result, the destruction, regeneration and the microenvironment creation for the propagation of these genetic changes have arisen. Although the technologies in HCC treatment and diagnosis have been continuously developed, the incidence of HCC and the mortality rate of HCC patients are still increasing annually. This trend results from defects in sensitivity and specificity during early detection, as well as less effective treatment in eliminating any remaining cancer cells.

Various other traditional HCC treatment modalities are available. These include surgical (hepatic resection) and non-surgical management, including percutaneous ethanol injection; PEI, or transcatheter arterial chemoembolization; TACE, or radiofrequency ablation; and RFA. Along with these modalities, the survival rates also depend on many other factors as well, especially on tumor size and staging (Osaki and Nishikawa, 2014). Alternatively, a targeted therapy such as immunotherapy via monoclonal antibodies (mAbs) specific to a tumor-associated antigen is a tool with fascinating prospects for the targeting of specific HCC cells, and is expected to lead to the eradication of tumors and the diminishing of their progression, while also reducing toxicity to normal cells. The assassinate mechanism of a cancer cell by monoclonal antibodies may be caused by its binding to (1) a cancer protein surface resulting in an immune-response (ADCC or CDC) induction, or (2) a growth-factor receptor that consequently blocks the cell's signaling capacity for cell growth (Li et al., 2013). In addition, a clinical trial for the use of the monoclonal antibody in its conjugated form is now extensively underway. The trial combines drugs or fluorescence as a means of inhibiting or destroying the cancer cells. With these advantages of the mAb, it has

${ }^{1}$ Faculty of Medicine, Thammasat University (Rangsit Campus), ${ }^{2}$ Thailand National Center for Genetic Engineering and Biotechnology (BIOTEC), Thailand Science Park, Pathum Thani, ${ }^{3}$ Antibody Production Research Unit, Institute of Biotechnology and Genetic Engineering, Chulalongkorn University, Bangkok, Thailand*For correspondence: panadda_rojpibulstit@hotmail.com 
been reported that several novel anti-HCC mAbs have now been identified (Yang and Roberts, 2010b; Ho, 2011).

In this regard, a Hep88 monoclonal antibody specific to hepatocellular carcinoma was produced by Laohathai and Bhamarapravati (Laohathai and Bhamarapravati, 1985). Our preliminary studies showed that Hep88 mAb has tumoricidal activity against the HCC (HepG2 cell line), while harmless to the normal liver cell line (Chang liver) (Puthong et al., 2009). Additionally, the Hep88 mAb's specific antigens, mortalin HSP70, which is a member of the chaperone heat shock protein 70 (Hsp70) family, and alpha-enolase have been recognized from proteomic study (Rojpibulstit et al., 2014). Moreover, the results from the study of ultracellular structural changes after treatment of the hepatocellular carcinoma HepG2 cell line with Hep88 $\mathrm{mAb}$ have shown that it induced the cytoplasmic massive vacuolization and mitochondrial swelling, but with the absence of chromatin condensation (Manochantr et al., 2011). These results imply that the death of HCC induced by Hep88 mAb was by way of a paraptosis-like program cell death (paraptosis-like PCD). The characteristic defined as paraptosis was the lacking of an apoptotic morphology, which might not respond through a caspases cascade pathway. Nonetheless, so many reports have to date pointed out that various types of cell death could be mutually stimulated on the detected cells, whereas the morphological change might be detected by the predominant one (Guo et al., 2010). Moreover, it has been reported that the contribution to becoming apoptosis- or paraptosis-PCD in colorectal cancer cells after treatment with ginsenoside $\mathrm{Rh} 2$ activation were not accounted as being only caspase- or non-caspase dependent ( $\mathrm{Li}$ et al., 2011). Rather, it was controllable through any other pathway which could trigger a cascade reaction via any of several kinds of protease activations, including, among others, caspase and cathepsin. Consequently, while the overlapping of various death routes was continuing to occur, more than one mechanism were able to be activated at the same time. It was, however, resulting in the turning up of only dominant ultrastructural change as was subsequently detected by electron micrograph.

In order to verify whether paraptosis-like PCD induced by Hep $88 \mathrm{mAb}$ against HCC was activated through caspase- or non-caspase dependency, we proceeded to investigate both the expression and activity of caspases in HCC-treated cells. The expression was detected with real-time PCR, while the enzyme activities were detected via colorimetric assay (BioVision Research Products, Mountain View, CA, USA). In addition, we determined active caspase- 3 presentation by flow cytometry. Therefore, rather than determining the mechanism involved in the Hep $88 \mathrm{mAb}$-induced cell death, the overall results from this study might be useful to get the proposed mechanism that will be necessary to develop new drugs for HCC treatment in the near future.

\section{Materials and Methods}

\section{Materials}

Fetal bovine serum, Trypsin/EDTA Solution and PBS solution were obtained from Biochrom (AG,
Berlin). TRI REAGENT ${ }^{\circledR}$ was obtained from Molecular research center, Inc. The oligo nucleotide primers (oligoDT primer), 2X Prime RT Premix and 2X Prime Q-Master Mix (with SYBR Green I) were obtained from BiOBiZ Corporation (Seoul, Korea). The BCA assay kit was purchased from Pierce (Rockford, IL, USA). The QIAprep ${ }^{\circledR}$ Spin Miniprep Kit was obtained from QIAGEN (Hilden, Germany). The InsTAclone PCR Cloning Kit was obtained from ThermoFisher Scientific (Pittsburgh, PA, USA). The Caspase-3/CPP32 Colorimetric assay kit, FLICE/Caspase-8 Colorimetric assay kit and Caspase-9 Colorimetric assay kit were purchased from BioVision Research Products (Mountain View, CA, USA). The FITC Active Caspase-3 Apoptosis Kit, BDFACS Rinse solution, BD FACS Clean solution and BD FACS Flow Sheath Fluid were purchased from BD Biosciences (CA, USA).

\section{Cell Lines and $m A b$}

Human HCC cell lines as HepG2 cells (American Type Culture Collection [ATCC] HB8065) were cultured in RPMI 1640 supplemented with $10 \%$ fetal bovine serum (Biochrom AG, Germany). The cell lines were maintained at $37^{\circ} \mathrm{C}$ in a $\mathrm{CO}_{2}$ incubator and subculture every 3-4 days until use. Hep88 mAb, the anti-HCC mouse mAb, was produced as previously described (Laohathai and Bhamarapravati, 1985).

HepG2 cells (6x10 cells) were cultivated in a 6-well culture plate with RPMI 1640 medium, which contained $10 \%$ fetal bovine serum, and incubated at $37^{\circ} \mathrm{C}$ in $5 \%$ $\mathrm{CO}_{2}$ for 24 hours prior to treatment. In this study, the concentrations of Hep88 mAb-treated HepG2 cells was $12.5 \mu \mathrm{g} / \mathrm{ml}\left(\mathrm{IC}_{50}\right.$ concentration from previous study), whereas the positive and negative control carried out in this study consisted of a chemotherapeutic drug, 0.06 $\mu \mathrm{g} / \mathrm{ml}$ doxorubicin-treated cells $\left(\mathrm{IC}_{50}\right.$ concentration from this study, data not shown) and untreated HepG2 cells, respectively. After 24, 48 and 72 hours of incubation, the cells were harvested by trypsinization with $0.05 \% / 0.02 \%$ trypsin/EDTA solution and were followed by washing twice with iced-cold PBS and centrifugation at 1,500 rpm. The cell pellet was collected for RNA extraction.

\section{RNA Extraction and cDNA Synthesis}

The total RNA was extracted by TRI REAGENT ${ }^{\circledR}$ according to the manufacturer's protocol (Molecular research center, Inc). The concentration and purity (A260/ A280 ratio) of RNA were measured using NanoDrop 1000 Spectrophotometer (NanoDrop Technologies, Inc. Wilmington, DE, USA) and then used as the template for first-strand complementary DNA (cDNA) synthesis. The reverse transcription reaction for converting RNA to cDNA contained oligo nucleotide primers (oligoDT primer) which were incubated at $70^{\circ} \mathrm{C}$ for 5 minutes, followed by reverse transcriptase (chilled them on ice for 1 minute and then added Prime RT Premix (BiOBiZ Corporation, Seoul, Korea) at $42{ }^{\circ} \mathrm{C}$ for 60 minutes. The enzyme activation was then stopped by heating at $70^{\circ} \mathrm{C}$ for 10 minutes. The cDNA concentration and A260/A280 were then measured using a NanoDrop 1000 Spectrophotometer (NanoDrop Technologies, Inc. Wilmington, DE, USA). 
Hep88 mAb-Mediated Paraptosis-Like to Apoptosis in HepG2 Cells via Activation of Caspase-3, Caspase-8 and Caspase-9

Plasmids Construction and Copy Number Determination

Caspase-3, Caspase-8, Caspase-9 and EF-2 gene were amplified by the conventional PCR method with the primer sets as shown in Table 1. The PCR product of each gene was cloned into the TA cloning vector $\mathrm{pTZ} 57 \mathrm{R} / \mathrm{T}$ using InsTAclone PCR Cloning Kit (ThermoFisher Scientific, Pittsburgh, PA, USA). The ligated vector was transformed into E. coli DH5 $\alpha$ competent cells by the heat shock method. The transformed culture was spread into LB plates containing ampicillin $(100 \mu \mathrm{g} / \mathrm{ml})$. The transformed colonies were picked and used for colony PCR technique. The plasmid extraction was performed using the QIAprep ${ }^{\circledR}$ Spin Miniprep Kit (QIAGEN, Hilden, Germany). The plasmid DNA concentration was measured and diluted to $100 \mathrm{ng} / \mu \mathrm{l}$ before sequencing. The sequence was analyzed by Macrogen Inc. (Korea) with the 96-capillary 3730xl DNA Analyzer (Applied Biosystems ${ }^{\circledR}$ ).

The plasmid DNA was diluted to (Serial Dilution) $10^{9}-10^{2}$. Diluted plasmid was added into the Real-time PCR Master mix. The gene expression was operated and analyzed by using the $\mathrm{iCycleriQ}^{\mathrm{TM}}$ Real-Time PCR Detection System (Bio-Rad Laboratories, Inc., Hercules, CA, USA). The data was reported as the Ct value of each dilution, which was then used in comparison with the copy number to generate the standard curve. The Copy Number was calculated from the plasmid DNA concentration using the following equation:

$$
\text { DNAcopy }=\frac{\left(6.02 \times 10^{23}(\mathrm{copy} / \mathrm{mol}) \times \mathrm{DNA} \text { amount }(\mathrm{g})\right.}{(\text { DNA length }(\mathrm{bp}) \times 660(\mathrm{~g} / \mathrm{mol} / \mathrm{bp})}
$$

\section{Real-Time PCR}

Real-time PCR was carried out in an $\mathrm{iCycleriQ}^{\mathrm{TM}}$ RealTime PCR Detection System (Bio-Rad Laboratories, Inc., Hercules, CA, USA). All samples were run in duplicate in a final reaction volume of $20 \mu \mathrm{l}$. Each sample contained $2 \mu 1$ of $500 \mathrm{ng} / \mu \mathrm{l}$ cDNA, $0.4 \mu \mathrm{l}$ of 10 @mol forward and reverse primers, DEPC water and $10 \mu \mathrm{l}$ of Prime Q-Master Mix with SYBR Green I (BiOBiZ Corporation, Seoul, Korea). The PCR parameters consisted of 1 cycle of initial denaturation at $94^{\circ} \mathrm{C}$ for $10 \mathrm{~min}$ and 40 cycles of amplification at $94^{\circ} \mathrm{C}, 60^{\circ} \mathrm{C}$ and $72^{\circ} \mathrm{C}$ for 30 seconds at each temperature level. The fluorescence signal was measured at the end of each extension step at $72{ }^{\circ} \mathrm{C}$. After the amplification, a melting curve analysis with a temperature gradient of $0.1{ }^{\circ} \mathrm{C} / \mathrm{s}$ was performed to confirm that only the specific products were amplified. The forward and reward primers used for PCR amplification of capase-3,-8,-9 and EF-2 as a control to normalize target gene expression are all listed in Table 1. The Forward and reverse primers were designed from Primer 3 (http://frodo. wi.mit.edu/), with specificity verified by the Basic Local Alignment Search Tool (http://www.ncbi.nlm.nih.gov/ blast/). The expression of the caspases was calculated by using both absolute quantification (achieved by comparing $\mathrm{Ct}$ values of the test sample to a standard curve) and relative quantification (the ratio of the relative amounts of targeted nucleic acid for equivalent amounts of test and control).

\section{Enzyme Colorimetric Assay}

After treating $1 \times 10^{6}$ HepG2 cells for 24,48 and 72 hours as described previously, cells were assayed for the induction of caspase activity according to the manufacturers' protocol. In brief, cells were harvested by trypsinization with $0.05 \% / 0.02 \%$ trypsin/EDTA solution followed by washing twice with iced-cold PBS and centrifugation at 1,500 rpm. Cells were then resuspended in $50 \mu \mathrm{l}$ of chilled cell lysis buffer and incubated on ice for 10 minutes. After centrifugation at $13,800 \mathrm{rpm}, 4^{\circ} \mathrm{C}$ for 20 minutes, protein concentration of the cytoplasmic lysate was determined by the $\mathrm{BCA}^{\mathrm{TM}}$ Protein Assay Kit (Pierce, Rockford, IL, USA). The protein concentration was adjusted to $100 \mu \mathrm{g} / 50 \mu \mathrm{l}$ with cell lysis buffer. The caspase-3,-8 and -9 activity was evaluated by using the Caspase-3/CPP32, FLICE/Caspase- 8 and Caspase-9 Colorimetric assay kit (BioVision Research Products, Palo Alto, CA, USA) according to the manufacturers' protocol. The cleavage of synthetic caspase-3 (DEVD-pNA), caspase-8 (IETD-pNA) and caspase-9 (LEHD-pNA) substrate were detected spectrophotometrically at 405$\mathrm{nm}$ in a microplate reader (BioTek, Winooski, VT, USA)

\section{Active Caspase-3 Staining and Determination}

Three-hundred thousand HepG2 cells were cultured in a 6-well plate and then treated with 50, 62.5 and 75 $\mu \mathrm{g} / \mathrm{ml}$ of Hep88 mAb for 24, 48 and 72 hours. The cells were permeabilized, fixed and stained for active caspase- 3 with the FITC Active Caspase-3 Apoptosis Kit follow the manufacturing's protocol. The results of active caspase- 3 staining were analyzed by fluorescence-activated cell sorter (FACS, BD FACSCalibur ${ }^{\mathrm{TM}}$, BD Biosciences, San Jose, CA, USA) with CellQuest ${ }^{\mathrm{TM}}$ software (BD Biosciences, San Jose, CA, USA).

\section{Statistical Analysis}

All data were expressed as a mean \pm SD. Difference between two groups was analyzed by One-way ANOVA and student's t test. $\mathrm{p}<0.05$ was considered statistically significant.

\section{Table 1. Forward and Reverse Primer Pcr Sequences ror Real-Time PCR}

\begin{tabular}{llccc}
\hline Primers & Sequence of Nucleotides (nt) & Size (nt) & Product Size \\
\hline Caspase-3 & Forward & 5'-TGT TTG TGT GCT TCT GAG CC-3' & 20 & $210 \mathrm{bp}$ \\
& Reverse & 5'-CAC GCC ATG TCA TCATCA AC-3' & 20 & \\
Caspase-8 & Forward & 5'-GAT CAA GCC CCA CGA TGA C-3' & 19 & $149 \mathrm{bp}$ \\
& Reverse & 5'-CCT GTC CAT CAG TGC CAT AG-3' & 20 & \\
Caspase-9 & Forward & 5'-CAT TTC ATG GTG GAG GTG AAG-3' & 21 & $149 \mathrm{bp}$ \\
& Reverse & 5'-GGG AAC TGC AGG TGG CTG-3' & 18 & \\
EF-2 & Forward & 5'-CTG AAG CGG CTG GCT AAG TCT GA-3' & 23 & $155 \mathrm{bp}$ \\
& Reverse & 5'-GGG TCA GAT TTC TTG ATG GGG ATG-3' & 24 & \\
\hline
\end{tabular}




\section{Results}

Plasmids Construction and Copy-Number Determination

The length of plasmid (bp) multiplied by the average weight of a double-stranded base pair $(660 \mathrm{~g} / \mathrm{mol} / \mathrm{bp})$ is a molecular weight of the plasmid. The copy number was calculated from the concentration of plasmid $(\mathrm{g})$, the Avogadro constant $\left(6.02 \times 10^{23} \mathrm{copy} / \mathrm{mol}\right)$ and the molecular weight $(\mathrm{g} / \mathrm{mol})$. The cloned plasmids were quantified and calculated as the copy number of each gene (Table 2). The standard curve of each gene was generated by serial dilution of plasmid. The standard curve of genes were linear in the range tested for $\mathrm{R}^{2}=0.999$ (caspase-3), $\mathrm{R}^{2}=0.997$ (caspase-8), $\mathrm{R}^{2}=0.995$ (caspase-9) and $\mathrm{R}^{2}=0.994$ (EF-2) as shown in Figure 1.

\section{Real-Time PCR}

Real-time PCR shows statistically significant differences in expression of caspase- 3 , caspase- 8 and caspase-9 $(\mathrm{p}<0.05)$ in Hep88-treated HepG2 (Figure 2).

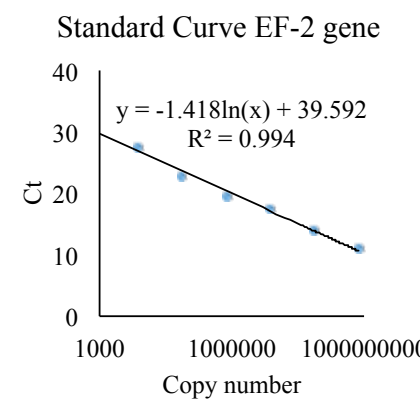

Standard Curve Caspase-8 gene
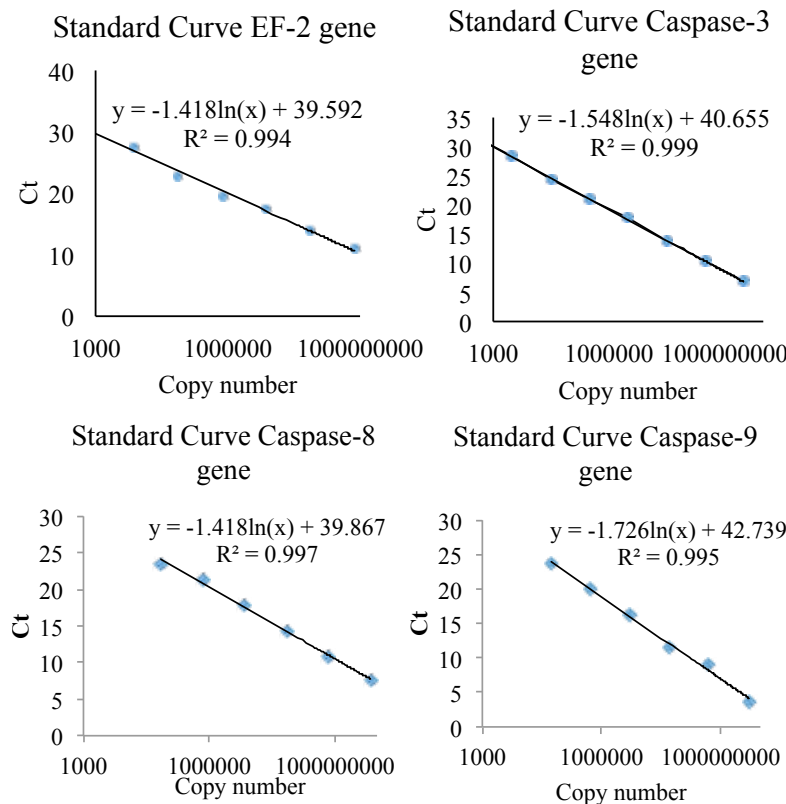

Standard Curve Caspase-9 gene

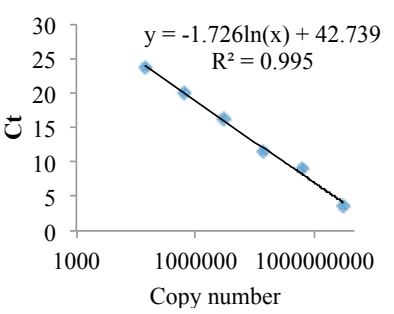

Figure 1. Standard curve for Caspase-3, -8, -9 and EF-2 Gene. The copy number of plasmid DNA template ranges from 109-102 copies. The standard curve of genes were linear in the range tested for $R^{2}=0.999$ (caspase-3), $R^{2}=0.997$ (caspase- 8 ), $\mathrm{R}^{2}=0.995$ (caspase-9) and $\mathrm{R}^{2}=0.994(\mathrm{EF}-2)$
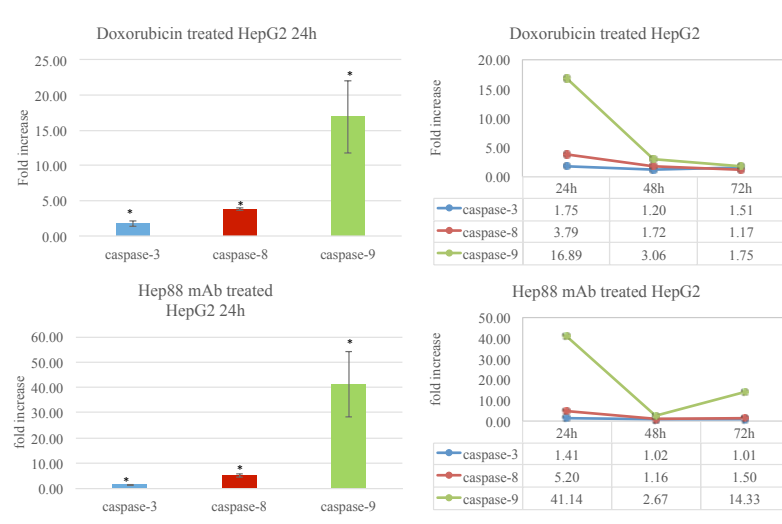

Figure 2. Effects on Caspase Expression of Doxorubicin and Hep88 Monoclonal Antibody-Treated HepG2 Cells. The line charts show fold change of caspase-3, $-8,-9$ gene expression in doxorubicin-treated HepG2 mRNA (upper) and Hep88-treated HepG2 mRNA (lower) after incubation for 24,48 and 72 hours. Data are expressed as fold changes, and are means \pm SDs $(\mathrm{n} \geq 3)$. $* \mathrm{p}<0.05 v s$. controls, $* * \mathrm{p}<0.001 v s$ controls
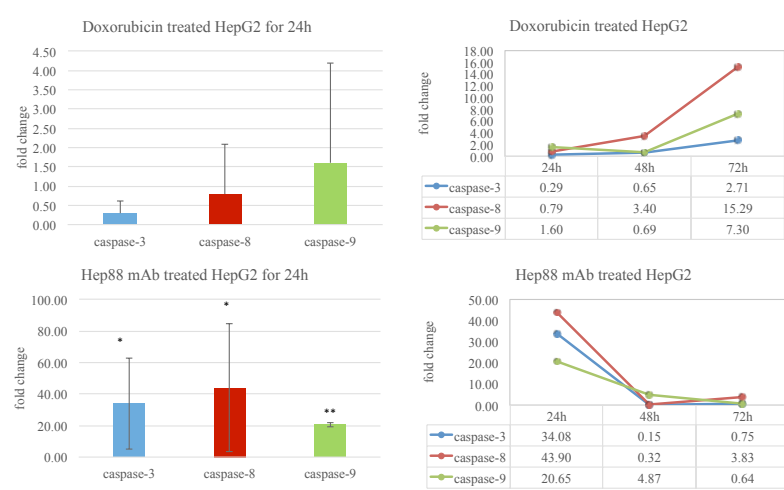

Figure 3. Effects on Caspase Activities of Doxorubicin and Hep88 Monoclonal Antibody-treated HepG2 Cells. The line charts show fold increases of caspase-3, -8, -9 enzyme activities in doxorubicin-treated HepG2 (upper) and Hep88treated HepG2 (lower) after incubation for 24,48 and 72 hours. The doxorubicin-treated HepG2 of caspase- $3,-8$ and -9 activities were increased at 24 hours, while the Hep88-treated HepG2 of caspase $-3,-8$ and -9 activities also increased highly during the first 24 hours. Effects on caspases activities were determined using HepG2 cells treated as described in the methods. Caspase activities in HepG2 were determined using the caspase-activity detection kits (see Methods). Data are expressed as fold increase, and as means $\pm \mathrm{SD}(\mathrm{n} \geq 3) * \mathrm{p}<0.05 v s$. control

Table 2. Calculation of Plasmid Copy Number

\begin{tabular}{llcccr}
\hline Gene & \multicolumn{1}{c}{ Plasmid } & $\begin{array}{c}\text { Length of } \\
\text { plasmid (bp) }\end{array}$ & $\begin{array}{c}\text { DNA concentration } \\
(\mathrm{ng} / \mu \mathrm{l})\end{array}$ & $\begin{array}{c}\text { Molecular } \\
\text { weight }\end{array}$ & Copy number \\
\hline caspase-3 & pTZ57R/T_caspase-3 & 3,096 & 106.25 & $2,043,360$ & $31,300,000,000$ \\
caspase-8 & pTZ57R/T_caspase-8 & 3,035 & 232.92 & $2,003,100$ & $70,000,000,000$ \\
caspase-9 & pTZ57R/T_caspase-9 & 3,035 & 172.35 & $2,003,100$ & $51,800,000,000$ \\
EF-2 & pTZ57R/T_EF-2 & 3,041 & 250.41 & $2,007,060$ & $75,108,795,460$ \\
\hline
\end{tabular}

Table 3. Effect of Hep88 Monoclonal Antibody on Active Caspase-3 Expression in HepG2

\begin{tabular}{lcccc}
\hline Time & \multicolumn{4}{c}{ Mean intensity } \\
\cline { 2 - 5 } & Control & $50 \mu \mathrm{g} / \mathrm{ml} \mathrm{Hep88} \mathrm{mAb}$ & $62.5 \mu \mathrm{g} / \mathrm{ml} \mathrm{Hep88} \mathrm{mAb}$ & $75 \mu \mathrm{g} / \mathrm{ml} \mathrm{Hep88} \mathrm{mAb}$ \\
\hline $24 \mathrm{~h}$ & $8.04 \pm 2.88$ & $7.67 \pm 2.51$ & $8.28 \pm 3.06$ & $9.12 \pm 3.20$ \\
$48 \mathrm{~h}$ & $7.99 \pm 2.16$ & $8.96 \pm 2.49$ & $9.28 \pm 2.70$ & $11.06 \pm 3.39$ \\
$72 \mathrm{~h}$ & $8.30 \pm 2.80$ & $10.41 \pm 3.33$ & $12.06 \pm 3.80^{*}$ & $13.89 \pm 4.46^{*}$ \\
\hline
\end{tabular}

$*(\text { mean } \pm \mathrm{SD}, \mathrm{n}=3)^{*} \mathrm{p}<0.05 v s$. control group 

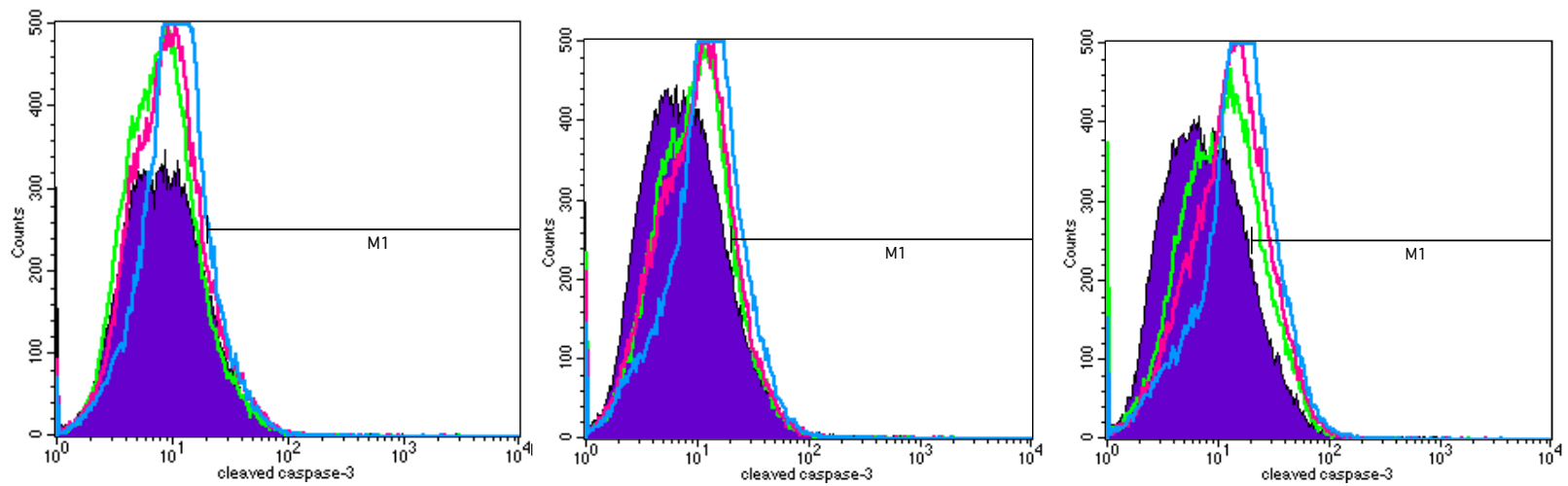

Figure 4. Effect of Hep88 Monoclonal Antibody on Active Caspase-3 in HepG2. The overlay untreated control HepG2 cell is shown with various Hep $88 \mathrm{mAb}$ concentrations during treatment at 24,48 and 72 hours. The mean intensity of active caspase- 3 showed a greater increase than in the control group in a dose- and time-dependent manner

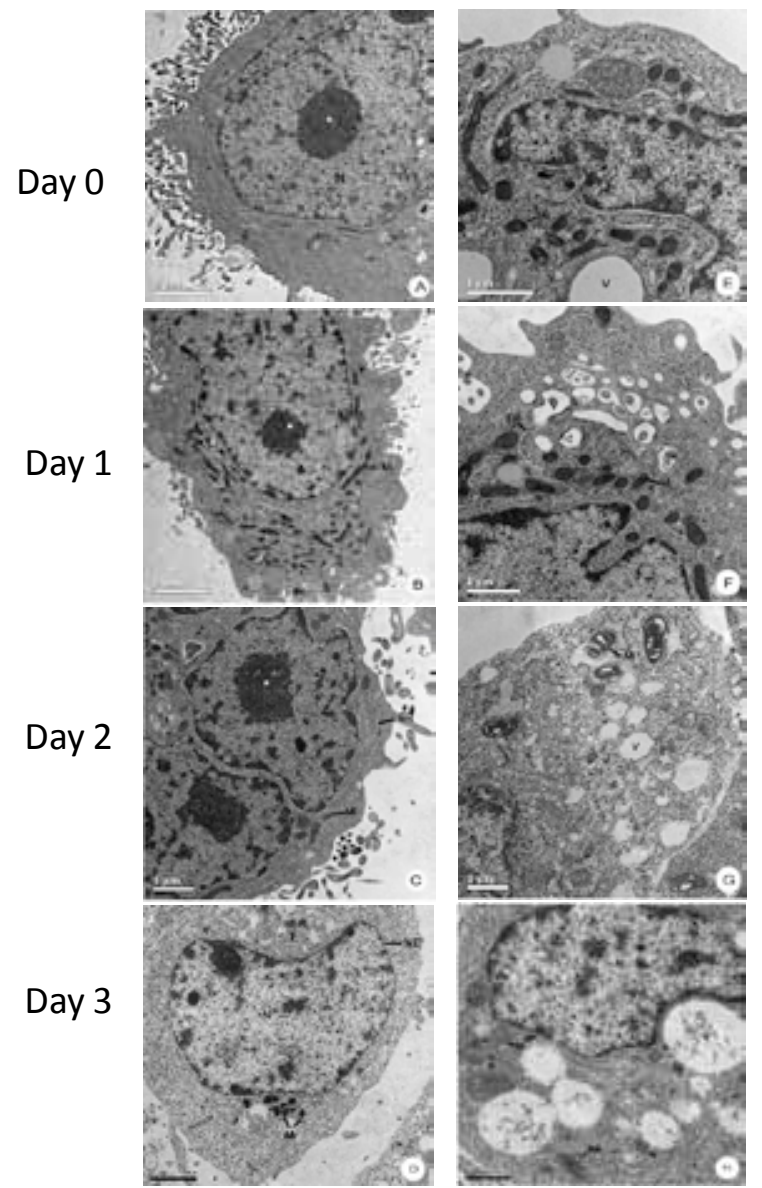

Figure 5.TEM Micrographs of Subcellular Alterations of the Chang (left) and HepG2 Cell Line (right) after Incubation with Hep88 mAb: day 0 (A,E), day $1(B, F)$, day $2(C, G)$, day $3(D, H)$. Gradual intracellular vacuolization within mitochondria and ER dilation were observed only in HepG2 treated cell). (reproduced with permission of Rojpibulstit, 2014 from the reference Rojpibulstit et al. (2014). "Hep88 mAb-initiated paraptosis-like PCD pathway in hepatocellular carcinoma cell line through the binding of mortalin (HSPA9) and alpha-enolase." Cancer Cell International 14.)

The expression of caspase-3, caspase- 8 and caspase- 9 was higher than in the control group after incubation for 24 hours (caspase- 3 : fold change $=34.08 \pm 29.01$; caspase-8: fold change: $43.90 \pm 40.48 ; \mathrm{p}<0.05$, caspase-9: fold change $=20.65 \pm 1.41 ; \mathrm{p}<0.001$; Figure 2 ). In addition, after incubation for 48 hours, the caspase- 3 and caspase- 8 expression in Hep88-treated HepG2 was significantly lower than in the control group (caspase-3: $0.15 \pm 0.14$; $\mathrm{p}<0.01$, caspase-8: $0.32 \pm 0.11 ; \mathrm{p}<0.01$; Figure 2). In the HepG 2 that had been treated with Doxorubicin for 48 and 72 hours, results show statistically significant differences in expression of caspase- 3 and caspase- $9(\mathrm{p}<0.05)$. By contrast, there were no statistically significant differences in HepG2 treated with Doxorubicin for 24 hours in expression of caspase- 3 , caspase-8 and caspase- 9 when compared with control $(\mathrm{p}>0.05)$.

\section{Caspase-3,-8,-9 colorimetric activities}

The activation of caspase activity is a unique feature of apoptotic cell death. We determined Hep88-induced activation of the protease activities of caspase-3, caspase- 8 and caspase-9. As shown in Figure. 3, caspase-3, caspase-8 and caspase-9 activities in doxorubicin-treated HepG2 $(1.748 \pm 0.37,3.786 \pm 0.21,16.889 \pm 7.22 ; \mathrm{p}<0.05)$ and Hep88 mAb-treated HepG2 $(1.412 \pm 0.15,5.197 \pm 0.90$, $41.228 \pm 18.192 ; \mathrm{p}<0.05)$ are significantly different at 24 hours following incubation. By contrast, at 48 and 72 hours, there was no significant effect on caspase-3, caspase- 8 and caspase- 9 activities in the HepG2 cells (except caspase- 8 and caspase- 9 in Hep88-treated HepG2 cell for $72 \mathrm{~h} ; 1.50 \pm 0.27$ and $14.334 \pm 5.19 ; \mathrm{p}<0.05$ respectively).

Effect of Hep $88 \mathrm{mAb}$ on an Active Caspase-3 Expression

After treatment with various concentrations of Hep $88 \mathrm{mAb}$, the mean intensity of the content in the samples increased, indicating increased active caspase- 3 . According to the concentration of Hep88 mAb at $72 \mathrm{~h}$, active caspase- 3 staining was $125.46 \%, 145.34 \%$ and $167.31 \%$ higher than in the control group, which was statistically significant as shown in Table 3 and Figure 4.

\section{Discussion}

Although many therapeutic strategies have shown a remarkable anticancer effect (Chua and Choo, 2011), toxicity of these conventional therapies to normal cells are nonetheless unavoidable. Currently, certain novel anticancer therapies that are effective while less toxic to normal cells are particularly interesting. Especially for the most life-threatening cancers (Yang and Roberts, 2010a) 
such as HCC, many of the anticancer drugs are involved in apoptosis induction (Yu et al., 2011; Al-Fatlawi et al., 2014; Jia et al., 2014). Among these, a targeted therapy like monoclonal antibody treatment appears to be a promising tool for successful treatment.

As shown in the recent report, Hep88 mAb was cytotoxic to the HCC cell line while harmless to the normal Chang liver cell line (Puthong et al., 2009). Additionally, Manochantr et al. (Manochantr et al., 2011; Rojpibulstit et al., 2014) also illustrated the intracellular vacuolization as well as the dilatation of endoplasmic reticulum and mitochondria of the HCC cell line following incubation with Hep $88 \mathrm{mAb}$. These morphological changes are easily compatible with those findings in paraptosis-like programmed cell death (PCD) as described by Sperandio et al. (Sperandio et al., 2000), Wyllie and Golstein (Wyllie and Golstein, 2001), whose explanations were generally based on a cascade reaction of a caspase-independent pathway. Alternatively, caspase-dependent regulatory pathway is morphologically described by those patterns of cytoplasmic shrinkage and chromatin condensation with DNA fragmentation, as well as the forming of apoptotic body with nuclear fragmentations. The death mechanism of cells, however, does not rely on only one mechanism but also depends on a multi-mechanism as well. The morphological changes actually depend on which processes are speeding up more and which are definitely ending up with the most effective and fastest pathway (Bursch, 2001; Leist and Jaattela, 2001; UnalCevik et al., 2004).

This ambiguous pathway is, hence, prodding us to identify the mechanism that is causing Hep88 mAb to be involved in the induction of HCC cell death. As a means of evaluating our hypothesis that the caspase enzyme may have had an actual involvement, we thus studied the up-regulation of both gene and enzyme activity of caspase- $3,-8$ and -9 in the hepatocellular carcinoma cell line (HepG2) after treatment with $12.5 \mu \mathrm{g} / \mathrm{ml}$ of the Hep88 monoclonal antibody ( $\mathrm{IC}_{50}$ concentration) for 24,48 and 72 hours. In addition, caspase- 3 induction in HepG 2 cells after being treated with a cytotoxic dose of Hep88 mAb concentrations (4-6 times of $\mathrm{IC}_{50}$ concentration) for 24, 48 and 72 hours were also investigated by flow cytometric detection using FITC Active Caspase-3 staining.

As we validated the real-time PCR product by plasmid construction after amplification by the conventional PCR method to test its reliability, the result showed that the regression analysis is extremely closed in linearity (Figure 1).These goodness-of-fit statistical results guaranteed that our real-time PCR results were of sufficient reproducibility to quantify those parameters of the caspase expression following incubation with Hep88 $\mathrm{mAb}$ as formerly discussed by Pfaffl M.W.and Hageleit M. (Pfaffl and Hageleit, 2001).

The quantitative real-time PCR results of our study confirmed the powerful potency of Hep88 mAb in the induction of HCC cell death by up-regulation of caspase-3,-8 and -9 genes expression after 24 hours of incubation. Altogether, those enzyme activities also increased significantly as compared with untreated cells. These outcomes were consistent with findings from other researchers (Del Puerto et al., 2010; Selim and Hendi, 2012; Gupta et al., 2013), which reported the apoptotic induction pathway significantly increased the presence of caspase-3, -8 and -9 expressions. Interestingly, when compared with the chemotherapeutic drug doxorubicin, an early and remarkably outstandingly apoptotic induction resulted. Hep $88 \mathrm{mAb}$ induced the up-regulation of the caspase cascade mechanism following 24 hours of incubation. Meanwhile, doxorubicin induced an upregulation of those three caspases in a time-dependent manner, i.e. from a slightly advanced stage of induction to a completely advanced stage of induction, from 24 hours to 72 hours as shown in Figure 2. From a comparison of those up-regulated fold changes of Hep88 $\mathrm{mAb}$ with doxorubicin, it was shown that our mAb more strongly activated caspase- 3 and -9 expressions than did doxorubicin $(\mathrm{p}<0.05)$. This result demonstrates its effectiveness over the common chemotherapeutic drugs normally that have been used in cancer therapy up to the present time.

The apoptotic mechanism induced by Hep88 mAb might be started either upon binding with its receptor or just after cellular internalization. Its effect is possible on both an extrinsic and intrinsic pathway. As regards the extrinsically proposed mechanism, it induced the activation of initiator caspase-8, which is the key substance of HCC-inducing apoptosis as reported by Cho et al. (Cho et al., 2010). It is subsequently the initiator of the caspase cascade reaction and also activates the effect of the caspase- 3 . Other than detecting the increasing caspase- 3 expression and activity, the caspase- 3 has also been confirmed as active following incubation with Hep88 $\mathrm{mAb}$ by using an antibody that specifically recognizes the active form of caspase-3 for staining (Table 3, Figure 4). The result correlated well with another analytical apoptosis study in a time- and dose-dependent manner. Alternatively, an intrinsic pathway is normally explained scientifically by a mitochondria-mediated mechanism from the formation of mitochondrion permeability transition pores (MPTPs). This process results in the releasing of cytochrome c, which thus stimulates the assembly of procaspase- 9 with Apaf-1 and cytochrome $\mathrm{c}$ itself to become an apoptosome. It then activates caspase-9, which then ultimately initiates caspase-3 activation (Gupta et al., 2009; Gupta et al., 2013). Other than cytochrome c, MPTPs also release a caspase-independent death effect or other effect such as the Apoptosis Inducing Factor (AIF), which ultimately signals the cell to become apoptosis by stimulating chromatin condensation and DNA fragmentation (Cande et al., 2002; Norberg et al., 2010). From these interactions, many researchers have tried to investigate this novel effect on molecules that may stimulate any of the responsible deathsignaling proteins or inhibit some of the apoptosis inhibitor in order to induce cancer into becoming apoptosis.

One of those interesting proteins is of the heat shock protein 70 (Hsp70) family, the molecular chaperone which is up-regulated in response to stress and cancer (Daugaard et al., 2007). It is accountable as an apoptosisinhibitor molecule after detecting the association of its over-expression with the poor prognosis of several cancers (Garrido et al., 2001; Ciocca and Calderwood, 
Hep88 mAb-Mediated Paraptosis-Like to Apoptosis in HepG2 Cells via Activation of Caspase-3, Caspase-8 and Caspase-9

2005; Rohde et al., 2005). The mechanisms involved in the anti-apoptosis of the Hsp70 family include blocking the recruitment of the procaspase- 9 assembly toward the apoptosome complex (Beere, 2004), which, for example, inhibits caspase- 3 apoptosis induction (Sabirzhanov et al., 2012) and prevents the release of AIF from mitochondria (Ruchalski et al., 2006).

Based on our recent report, which demonstrated that Hep88 mAb's specific cytoplasmic protein is a protein in the Hsp70 family mortalin (Hsp70-9, Grp75) (Rojpibulstit et al., 2014). Mortalin is commonly over-expressed in various cancer types (Wadhwa et al., 2006; Deocaris et al., 2007; Kaul et al., 2007). Its function is normally explained as the suppression of the activation of the mitochondrial apoptotic cascade by inhibiting either cytochrome c release or caspase-3 activation (Qu et al., 2012). As a result, cancer cells were prevented from apoptosis. Based on this fact and in light of our results, it might be postulated that this apoptosis-inhibiting mechanism is refrained after incubation with Hep88 mAb. Once Hep 88 mAb interacted with mortalin, which is its specific antigen, it subsequently resulted in recovering the caspase- 3 cascade mechanism which conducted the apoptosis pathway in the final stage. Moreover, Wadhwa et al. also reported that mortalin can bind to the tumor-suppressor protein p53, emerging as the mortalin-p53 interaction formation (Wadhwa et al., 2002). This interaction formation results in a de-regulated p53 function. Once the apoptosis event is ultimately prevented, cells then essentially become immortal and transform into cancer (Ma et al., 2006). Lu et al., however, just reported that HepG2 is unlike most of the HCC cancer cells lines, since the mortalin-p53 interaction depends on the cellular stress levels (Lu et al., 2011). As based on this point, and as in our previous report (Rojpibulstit et al., 2014), this dependency yet again also demonstrated the up-regulated state of mortalin in the HepG2 cell line after being treated with Hep88 mAb. This condition results in the eventual interfering and rendering of the mortalin-p53 interaction. Thus, the other postulated apoptotic mechanism of Hep88 $\mathrm{mAb}$ consists in the regaining of $\mathrm{p} 53$-mediated apoptosis by withdrawal of mortalin action on $\mathrm{p} 53$. The p53 then translocates itself into a nucleus and induces apoptotic signals. It does, however, require more information for clarification, as our outcomes show considerable promise for the possibility of the Hep88 mAb mechanism on the induction program cell death of HCC.

In summary, from all of the evidence emerging from our studies, the effects of the specific recognition between Hep88 mAb and the Hsp70 family mortalin in the cytoplasmic of HCC cells made it possible for an internal caspase cascade mechanism to be stimulated through the blocking of the Hsp70 mortalin anti-apoptotic function. This action thus promotes the caspases- 9 activation, caspase-3 activation and, finally, the apoptosis process (Ravagnan et al., 2001; Beere, 2004; Sreedhar and Csermely, 2004; Zhu et al., 2009; Jiang et al., 2014). Those patterns of caspase-3, -8 and -9 activations, including both the expression and activity that followed induction by Hep $88 \mathrm{mAb}$, constitute strong evidence in support of the potential of our monoclonal antibody as the targeted therapy for $\mathrm{HCC}$ in the near future.
Last but not least, as shown in our previous studies, HCC cell line treatment with Hep88 represented the paraptosis morphology, i.e. intracellular vacuolization, mitochondrial- and ER-swelling as shown in Figure 5. In this present study, we found the death of incubated cells that had been involved in the induction of caspase-3, caspase- 8 and caspase- 9 during the early treatment of $\mathrm{IC}_{50}$ dose of Hep88 mAb (24 hours). This result correlated well with those discussed by $\mathrm{Li} \mathrm{B}$ et al. which demonstrated that cell death after ginsenoside Rh2 treatment mediated both caspase-dependent apoptosis and caspase-independent apoptosis by p53-mediated cell death (Li et al., 2011). They each caused a different death mechanism in cancer cells in a concentration- and time-dependent manner. These data support the earlier controversy that there is cross-communication between apoptotic and nonapoptotic programmed cell death (Sperandio et al., 2000). The cells can be activated by more than one mechanism at the same time and the dominant cell death morphology is determined by the speed of those mechanisms (Wyllie and Golstein, 2001).

In summary, along with the target specificity of Hep88 $\mathrm{mAb}$, it shows strongly evident on the toxicity to HCC. It mainly induces paraptosis through apoptosis by activation of caspase cascade reaction both extrinsic and intrinsic pathway by concentration- and time-dependent manner. This implies that Hep88 mAb might be the promising tool for effective treatment of HCC in the near future.

In conclusion, Although it has been suggested that paraptosis is involved in the anti-cancer activity of Hep $88 \mathrm{mAb}$, the results from this study demonstrated that Hep88 mAb can induce HepG2 to apoptosis by leading to downstream induction of caspase-3, caspase- 8 and caspase-9, for which the mRNA expressions were also up-regulated. However, further study on the expression of Bax, Bcl-2 family protein, p53 as well as cathepsin and other related topics is warranted in order to confirm the cellular and molecular mechanisms underlying anticancer activities of Hep $88 \mathrm{mAb}$ in sufficient detail. These activities should be further investigated.

\section{Acknowledgements}

This work was financially supported by the research grant from Faculty of Medicine, Thammasat University. TM is supported by Thammasat University Ph.D. Program scholarship.

\section{References}

Al-Fatlawi AA, Al-Fatlawi AA, Irshad M, et al (2014). Rice bran phytic acid induced apoptosis through regulation of Bcl-2/Bax and p53 genes in HepG2 human hepatocellular carcinoma cells. Asian Pac J Cancer Prev, 15, 3731-6.

Beere HM (2004). "The stress of dying": the role of heat shock proteins in the regulation of apoptosis. J Cell Sci, 117, 2641-51.

Bursch W (2001). The autophagosomal-lysosomal compartment in programmed cell death. Cell Death Differ, 8, 569-81.

Cande C, Cohen I, Daugas E, et al (2002). Apoptosis-inducing factor (AIF): a novel caspase-independent death effector released from mitochondria. Biochimie, 84, 215-22. 
Cho S, Lee JH, Cho SB, et al (2010). Epigenetic methylation and expression of caspase 8 and survivin in hepatocellular carcinoma. Pathol Int, 60, 203-11.

Chua CW, Choo SP (2011). Targeted therapy in hepatocellular carcinoma. Int J Hepatol, 2011, 348297.

Ciocca DR, Calderwood SK (2005). Heat shock proteins in cancer: diagnostic, prognostic, predictive, and treatment implications. Cell Stress Chaperones, 10, 86-103.

Daugaard M, Rohde M, Jaattela M (2007). The heat shock protein 70 family: Highly homologous proteins with overlapping and distinct functions. FEBS Lett, 581, 3702-10.

Del Puerto HL, Martins AS, Moro L, et al (2010). Caspase-3/-8/-9, Bax and Bcl-2 expression in the cerebellum, lymph nodes and leukocytes of dogs naturally infected with canine distemper virus. Genet Mol Res, 9, 151-61.

Deocaris CC, Widodo N, Ishii T, et al (2007). Functional significance of minor structural and expression changes in stress chaperone mortalin. Ann N Y Acad Sci, 1119, 165-75.

Ferlay J, Shin HR, Bray F, et al (2010). Estimates of worldwide burden of cancer in 2008: GLOBOCAN 2008. Int J Cancer, 127, 2893-917.

Garrido C, Gurbuxani S, Ravagnan L, et al (2001). Heat shock proteins: endogenous modulators of apoptotic cell death. Biochem Biophys Res Commun, 286, 433-42.

Guo WJ, Chen TS, Wang XP, et al (2010). Taxol induces concentration-dependent apoptotic and paraptosis-like cell death in human lung adenocarcinoma (ASTC-a-1) cells. $J$ Xray Sci Technol, 18, 293-308.

Gupta RK, Banerjee A, Pathak S, et al (2013). Induction of mitochondrial-mediated apoptosis by Morinda citrifolia (Noni) in human cervical cancer cells. Asian Pac J Cancer Prev, 14, 237-42.

Gupta S, Kass GE, Szegezdi E, et al (2009). The mitochondrial death pathway: a promising therapeutic target in diseases. J Cell Mol Med, 13, 1004-33.

Ho M (2011). Advances in liver cancer antibody therapies: a focus on glypican-3 and mesothelin. BioDrugs, 25, 275-84.

Jia ZQ, Chen Y, Yan YX, et al (2014). Iso-suillin isolated from Suillus luteus, induces G1 phase arrest and apoptosis in human hepatoma SMMC-7721 cells. Asian Pac J Cancer Prev, 15, 1423-8.

Jiang L, Liu M, Li Y, et al (2014). Abstract 1559: TTC36, a novel chaperone of heat shock protein 70 , functions as a tumor suppressor in hepatocellular carcinoma. Cancer Res, 74, 1559.

Kaul SC, Deocaris CC, Wadhwa R (2007). Three faces of mortalin: a housekeeper, guardian and killer. Exp Gerontol, 42, 263-74.

Laohathai K, Bhamarapravati N (1985). Culturing of human hepatocellular carcinoma. A simple and reproducible method. Am J Pathol, 118, 203-8.

Leist M, Jaattela M (2001). Four deaths and a funeral: from caspases to alternative mechanisms. Nat Rev Mol Cell Biol, 2, 589-98.

Li B, Zhao J, Wang CZ, et al (2011). Ginsenoside Rh2 induces apoptosis and paraptosis-like cell death in colorectal cancer cells through activation of p53. Cancer Lett, 301, 185-92.

Li GN, Wang SP, Xue X, et al (2013). Monoclonal antibodyrelated drugs for cancer therapy. Drug Discov Ther, 7, 178-84.

Lu WJ, Lee NP, Kaul SC, et al (2011). Mortalin-p53 interaction in cancer cells is stress dependent and constitutes a selective target for cancer therapy. Cell Death Differ, 18, 1046-56.

Ma Z, Izumi H, Kanai M, et al (2006). Mortalin controls centrosome duplication via modulating centrosomal localization of p53. Oncogene, 25, 5377-90.

Manochantr S, Puthong S, Gamnarai P, et al (2011). Hep 88
$\mathrm{mAB}$ induced ultrastructural alteration through apoptosis like program cell death in hepatocellular carcinoma. J Med Assoc Thai, 94, 109-16.

Norberg E, Orrenius S, Zhivotovsky B (2010). Mitochondrial regulation of cell death: processing of apoptosis-inducing factor (AIF). Biochem Biophys Res Commun, 396, 95-100.

Osaki Y, Nishikawa H (2014). Treatment for hepatocellular carcinoma in Japan over the last three decades: Our experience and published work review. Hepatol Res.

Pfaffl MW, Hageleit M (2001). Validities of mRNA quantification using recombinant RNA and recombinant DNA external calibration curves in real-time RT-PCR. Biotechnology Letters, 23, 275-82.

Puthong S, Rojpibulstit P, Buakeaw A (2009). Cytotoxic effect of Hep88 mAb: a novel monoclonal antibody against hepatocellular carcinoma. Thammasat Int J Sc Tech, 14, 95-104.

Qu M, Zhou Z, Chen C, et al (2012). Inhibition of mitochondrial permeability transition pore opening is involved in the protective effects of mortalin overexpression against betaamyloid-induced apoptosis in SH-SY5Y cells. Neurosci Res, 72, 94-102.

Ravagnan L, Gurbuxani S, Susin SA, et al (2001). Heat-shock protein 70 antagonizes apoptosis-inducing factor. Nat Cell Biol, 3, 839-43.

Rohde M, Daugaard M, Jensen MH, et al (2005). Members of the heat-shock protein 70 family promote cancer cell growth by distinct mechanisms. Genes Dev, 19, 570-82.

Rojpibulstit P, Kittisenachai S, Puthong S, et al (2014). Hep88 mAb-initiated paraptosis-like $\mathrm{PCD}$ pathway in hepatocellular carcinoma cell line through the binding of mortalin (HSPA9) and alpha-enolase. Cancer Cell Int, 14, 69-78.

Ruchalski K, Mao H, Li Z, et al (2006). Distinct hsp70 domains mediate apoptosis-inducing factor release and nuclear accumulation. J Biol Chem, 281, 7873-80.

Sabirzhanov B, Stoica BA, Hanscom M, et al (2012). Overexpression of HSP70 attenuates caspase-dependent and caspase-independent pathways and inhibits neuronal apoptosis. J Neurochem, 123, 542-54.

Selim ME, Hendi AA (2012). Gold nanoparticles induce apoptosis in MCF-7 human breast cancer cells. Asian Pac J Cancer Prev, 13, 1617-20.

Somboon K, Siramolpiwat S, Vilaichone RK (2014). Epidemiology and survival of hepatocellular carcinoma in the central region of Thailand. Asian Pac J Cancer Prev, 15, 3567-70.

Sperandio S, de Belle I, Bredesen DE (2000). An alternative, nonapoptotic form of programmed cell death. Proc Natl Acad Sci U S A, 97, 14376-81.

Sreedhar AS, Csermely P (2004). Heat shock proteins in the regulation of apoptosis: new strategies in tumor therapy: a comprehensive review. Pharmacol Ther, 101, 227-57.

Unal-Cevik I, Kilinc M, Can A, et al (2004). Apoptotic and necrotic death mechanisms are concomitantly activated in the same cell after cerebral ischemia. Stroke, 35, 2189-94.

Wadhwa R, Taira K, Kaul SC (2002). An Hsp70 family chaperone, mortalin/mthsp70/PBP74/Grp75: what, when, and where? Cell Stress Chaperones, 7, 309-16.

Wadhwa R, Takano S, Kaur K, et al (2006). Upregulation of mortalin/mthsp70/Grp75 contributes to human carcinogenesis. Int J Cancer, 118, 2973-80.

Wyllie AH, Golstein P (2001). More than one way to go. Proc Natl Acad Sci USA, 98, 11-3.

Yang JD, Roberts LR (2010a). Epidemiology and management of hepatocellular carcinoma. Infect Dis Clin North Am, 24, 899-919.

Yang JD, Roberts LR (2010b). Hepatocellular carcinoma: A 
Hep88 mAb-Mediated Paraptosis-Like to Apoptosis in HepG2 Cells via Activation of Caspase-3, Caspase-8 and Caspase-9 global view. Nat Rev Gastroenterol Hepatol, 7, 448-58.

Yu J, Zhou X, He X, et al (2011). Curcumin induces apoptosis involving bax/bcl-2 in human hepatoma SMMC-7721 cells. Asian Pac J Cancer Prev, 12, 1925-9.

Zhu Q, Xu YM, Wang LF, et al (2009). Heat shock protein 70 silencing enhances apoptosis inducing factor-mediated cell death in hepatocellular carcinoma HepG2 cells. Cancer Biol Ther, $8,792-8$. 